\title{
Study on optimization of repair process in gear transmission box
}

\author{
Mei-jie Zhai ${ }^{1, a}$, Peng Gao ${ }^{2, b}$ \\ ${ }^{1}$ Mechanical Engineering Department of Armored Engineering College, Beijing China, 100072 \\ ${ }^{2}$ Bohai Polytechnic Vocational College, Hebei China, 061100 \\ a18222785009@163.com, bsanmu@qq.com
}

Key words: gear transmission box; Medium repair process; process optimization;

Absrtact. In order to improve the efficiency and benefit of equipment maintenance, reduce the maintenance cost, we need to optimize the repair process of armored equipment. First of all, the paper analyzes the process flow and influence factors of the gear transmission box, and determines the optimization target of the repair total working hours and man-hour cost, and the personnel and resources allocation of the medium repair process as the optimization index. Then, the calculation relation between personnel ability, material resource and maintenance time is determined, and the process flow of gear transmission box is modeled and analyzed through the overall diagram. Finally, through the analysis and research of different personnel configuration and different maintenance tools configuration of different schemes, The optimal resource allocation and maintenance process for gear box repair is confirmed, and the effectiveness and advanced nature of the technology in equipment maintenance process planning are validated.

\section{Introduction}

Weapon equipment is an important part of Army combat effectiveness, and timely and reliable equipment maintenance is the important guarantee to maintain, restore and even improve the combat effectiveness of the Army. In recent years, with the evolution of various operational concepts and operational styles and the application of various high and new technology in equipment, more and more requirements have been put forward for equipment maintenance, and the maintenance work is becoming more and more complex [1].

As the core component of maintenance support system, armored equipment maintenance plays an important role in improving the efficiency of maintenance support system and improving equipment readiness. At present, our Army's armored equipment maintenance organizations are mainly divided into base-level maintenance (overhaul), Relay level maintenance (intermediate repair) and basic level maintenance (minor repairs) three levels, among which the equipment medium repair Organization is peacetime and the wartime most main direct support strength, in the maintenance safeguard system occupies the extremely important position [2]. On the one hand, our army training tasks and exercise tasks gradually increased, the maintenance and support task of armored equipment has put forward stricter requirements on equipment in both quantity and time. On the other hand, the ability and composition of the technicians in the medium-repair institutions are changing greatly, which provides a solid foundation for improving the capability of equipment maintenance. Therefore, in order to meet the operational and training needs of the troops and to maximize the utilization rate of maintenance resources, the repair process must be more accurately scheduled and controlled in order to improve the efficiency of equipment maintenance.

The repair of single equipment is the most common maintenance service in the medium repair institution, in which the optimization of repair process is the key to improve the efficiency of armor 
equipment maintenance [3]. In this paper, through the analysis of the factors affecting the repair process in the gear box, the plan of the middle repair process and the optimization of the process plan in order to provide guidance for the process optimization of armored equipment.

\section{Analysis of influencing factors}

\section{Human Resources analysis}

Personnel is the main part of the maintenance activities, is one of the main components of the maintenance operations, the role of personnel in the maintenance work is mainly reflected in the following two aspects: first, the maintenance of the design plan, the second is the implementation of maintenance operations and operations [4]. The maintenance work process is carried out according to the already established process, and the influence of the organization and management personnel on the medium repair ability is mixed with many subjective factors, so the optimization analysis only considers the operator who actually carries on the maintenance operation.

Maintenance personnel can analyze from three aspects: manipulative attitude, proficiency and technical level. In the aspect of manipulation, some workers have the phenomenon of inattention and laziness; proficiency, there is a large difference in the speed of disassembly and installation of workers with different proficiency levels; technical level, the level of technical staff can only complete a simple repetitive work, part of the work on the technical level has a certain demand [5]. The maintenance proficiency and the technical level are the main limiting factors of the maintenance personnel's working ability, as the factor of the optimization evaluation.

\section{Material Resources Analysis}

Material resources refer to the tools, equipment and energy needed for equipment maintenance [6]. Tool refers to the equipment maintenance needs to assist the use of goods, general functions and use are relatively simple, such as open wrenches, hammers and so on. Equipment is one of the necessary material conditions for maintenance operations, including disassembly and installation of equipment, handling equipment, metering equipment, calibration equipment, testing equipment, testing and fault diagnosis equipment, processing equipment, welding equipment. Energy refers to water, electricity, gas and so on for equipment maintenance. Maintenance tools and equipment is the main constraint to the maintenance of "work step" implementation, this article mainly analyzes these two aspects.

\section{Cost Resources analysis}

The expenses of the repairs include: maintenance staff hours, maintenance equipment costs, work consumables and miscellaneous expenses [7, 8]. Among the above-mentioned fees, equipment usage fee and work consumables cost have little effect on the expense expenditure of medium repair process, and maintenance man-hour cost is the main factor that causes different expense of medium repair process. Therefore, the selection of maintenance hours as a single factor to evaluate the merits of the maintenance process.

\section{Medium Repair Process modeling}

\section{Personnel capacity and Man-hour cost calculation method}

The process of equipment repair is composed of a large number of jobs with different technology and different technical difficulties. This paper takes the case of equipment chassis maintenance as an example to study, the chassis maintenance operation has different difficulty degree, the technical content and the importance, this has proposed the different request to the maintenance personnel's ability. It is complicated to evaluate the maintenance ability of maintenance workers, and use the 
Delphi investigation method to determine the important factors that affect the technical ability of maintenance personnel and the corresponding weights of each evaluation factor. Through the investigation, the most important factors are determined: the time of employment, physical fitness, training experience, education, the weight of the values are $0.5,0.2,0.2,0.1$.

Our army currently has a total of four levels in the chassis maintenance positions: Soldiers, junior workers, mid-level workers and senior workers. According to the responsibilities of different levels of work and work norms to determine the level of the various levels of influence factors, and to quantify the level of the various factors, the ability of different positions to calculate the standard values, as shown in table 1.

Table 1 standard of achievement standard

\begin{tabular}{|c|c|c|c|c|c|}
\hline $\begin{array}{l}\text { Analysis } \\
\text { factors }\end{array}$ & Time & $\begin{array}{c}\text { Physical } \\
\text { ability }\end{array}$ & $\begin{array}{c}\text { Training } \\
\text { experience }\end{array}$ & $\begin{array}{l}\text { Educational } \\
\text { background }\end{array}$ & $\begin{array}{c}\text { Standard } \\
\text { value }\end{array}$ \\
\hline Soldiers & $\begin{array}{c}1 \sim 2 \\
\operatorname{years}(60)\end{array}$ & $\begin{array}{c}\text { excellent } \\
(90) \\
\end{array}$ & $\begin{array}{l}\text { military area } \\
\text { training }(60)\end{array}$ & $\begin{array}{c}\text { technical } \\
\text { school }(60)\end{array}$ & 66 \\
\hline $\begin{array}{c}\text { Junior } \\
\text { engineer }\end{array}$ & $\begin{array}{c}3 \sim 5 \\
\operatorname{years}(70)\end{array}$ & $\operatorname{good}(80)$ & $\begin{array}{l}\text { big maintenance } \\
\text { factory }(75)\end{array}$ & $\begin{array}{c}\text { high school } \\
(70)\end{array}$ & 73 \\
\hline $\begin{array}{c}\text { Intermediate } \\
\text { workers }\end{array}$ & $\begin{array}{c}6 \sim 9 \\
\text { years }(80)\end{array}$ & medium(70) & $\begin{array}{l}\text { big maintenance } \\
\text { factory }(75)\end{array}$ & $\begin{array}{c}\text { Junior } \\
\text { College (80) } \\
\end{array}$ & 77 \\
\hline $\begin{array}{c}\text { Senior } \\
\text { workers }\end{array}$ & $\begin{array}{c}10 \text { years } ~ \\
(90)\end{array}$ & generally $(60)$ & $\begin{array}{l}\text { Professional } \\
\text { Colleges (90) }\end{array}$ & $\begin{array}{l}\text { undergraduate } \\
\qquad(90)\end{array}$ & 84 \\
\hline
\end{tabular}

In table 1, the standard value of personnel capability is given, and when a maintenance worker meets a technical level requirement in each parameter and does not meet the higher level a requirement, the maintenance technician is considered to be of this level. At the same time, the relative maintenance capacity of the same level of personnel also exists a certain gap, through a comprehensive assessment of the scores of various factors to calculate the worker's ability to score.

Take a maintenance worker for example: The working time is four years, the physical fitness is above average, the training experience for the overhaul plant internship, education for college. According to the conditions of the maintenance workers can be preliminarily determined between the primary workers and intermediate workers, the evaluation of the specific score of $75,77,75,80$, after the weight of the repairman must be divided into 75.9, the determination of the junior workers, the relative working capacity of 1.04 . Because the serviceability value of the maintenance staff is negatively correlated with the maintenance hours, the maintenance worker spends 0.962 times times as much work time on the same job as standard work.

\section{Evaluation method of material resources and man-hour cost}

Maintenance personnel is not the only factor affecting the equipment repair process, maintenance facilities, machinery and equipment, equipment, such as the completion of equipment repair necessary maintenance resources, will also have a greater impact on the process of equipment repair. In the maintenance and support resources protection, the research of maintenance spare parts is mainly to determine the type, quantity and reserve plan of spare parts reserve. According to the requirement of spare parts consumption in the process of long-term equipment maintenance and support, this paper simplifies the maintenance spare parts in the maintenance process, and considers that the preparation of maintenance spare parts in kind and quantity is sufficient, which ignores the time delay caused by spare parts raising.

The maintenance equipment is large to the comprehensive equipment test-bed, small to general-purpose wrench, not only includes the special equipment, but also has the general equipment, involves the electronic, the mechanical, the hydraulic and so on various work way. The improper configuration and use of maintenance equipment will not only affect the efficiency of equipment maintenance, but also cause great waste, sometimes it may even cause some processes to 
develop normally. Therefore, in order to ensure the maintenance task, the process is completed on time, as far as possible to compress the number of maintenance equipment configuration, improve its utilization, reduce maintenance costs. According to the maintenance experience to determine the maintenance efficiency of different maintenance equipment, the maintenance hours and the efficiency value of maintenance resources is inversely proportional to the gear box maintenance of the general maintenance machinery and equipment For example analysis, as shown in table 2.

Table 2 maintenance resource efficiency table

\begin{tabular}{|c|c|c|}
\hline Match category & Tool name & Efficiency value \\
\hline \multirow{2}{*}{$\begin{array}{l}\text { Shaft Hole } \\
\text { Disassembly }\end{array}$} & Big hammer & 1.0 \\
\hline & Press & 2.0 \\
\hline \multirow{4}{*}{$\begin{array}{c}\text { Assembly and } \\
\text { disassembly of bolted } \\
\text { joints }\end{array}$} & Open wrench & 1.0 \\
\hline & Socket wrench & 1.2 \\
\hline & Electric wrench P16Nm & 2.0 \\
\hline & Electric wrench P100Nm & 2.5 \\
\hline \multirow{3}{*}{ Snap ring removing } & Screwdriver $8^{\prime \prime}$ & 1.0 \\
\hline & Screwdriver $12^{\prime \prime}$ & 1.2 \\
\hline & Clasp clamp & 2.0 \\
\hline shaft and hole mating & Punch & 1.0 \\
\hline Disassembly gasket & Flat shovel & 1.0 \\
\hline
\end{tabular}

\section{Calculation method of Man-hour fee}

The maintenance Man-hour fee is the main factor which causes the different medium repair process plan expense expense difference, therefore, chooses the maintenance time expense to measure the maintenance craft plan good or bad standard. Working hours are mainly affected by two aspects: people and materials. Because of the different technical level, there is a great difference in the cost of the staff, and it needs to be considered synthetically, ignoring the price difference of the material itself, only considering the effect of the material on the efficiency. Here to each post grade maintenance personnel Unit Man-hour expense carries on the demarcation, the concrete expense is shown in table 3.

Table 3 Maintenance staff hours (data for reference only)

\begin{tabular}{l|l|l|l|l}
\hline Technical level & Soldier $\mathrm{C}_{1}$ & $\begin{array}{l}\text { Junior } \\
\mathrm{C}_{2}\end{array}$ & intermediate worker $\mathrm{C}_{3}$ & senior worker $\mathrm{C}_{4}$ \\
\hline Fee $(\mathrm{RMB} / \mathrm{h})$ & 4.5 & 8 & 10 & 12 \\
\hline
\end{tabular}

\section{Central Repair Plan modeling}

The plan is to fully visualize the whole process of equipment maintenance and the logical relationship between each stage and process by means of graphic simulation, so that all personnel can understand the whole production process, and it is beneficial to cooperate and coordinate. The main process of the gear box repair is shown in Figure 1.

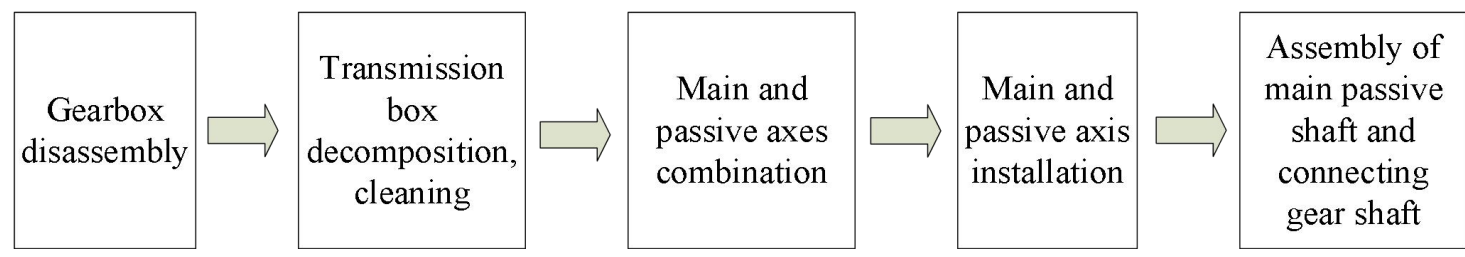

Fig 1 Flow chart of gear box 
According to the above process to determine the key route of the middle repair process, calculate and analyze the boundary time of each task, and make maintenance personnel for each maintenance task, then describe the medium repair process plan in a more intuitive and feasible way, and coordinate the plan of the gear transmission box in the process of the overhaul [9], as shown in Fig. 2, a two-arrow line is clearly given in the figure to fix the key route, and the constraint relationship between the maintenance tasks is described by other different types of arrows, and the nodes in the graph indicate the earliest and latest time to end the maintenance process. The process, the number of maintenance personnel and the amount of man-hour determined (as per the time the soldier completes the process are standard) [10].

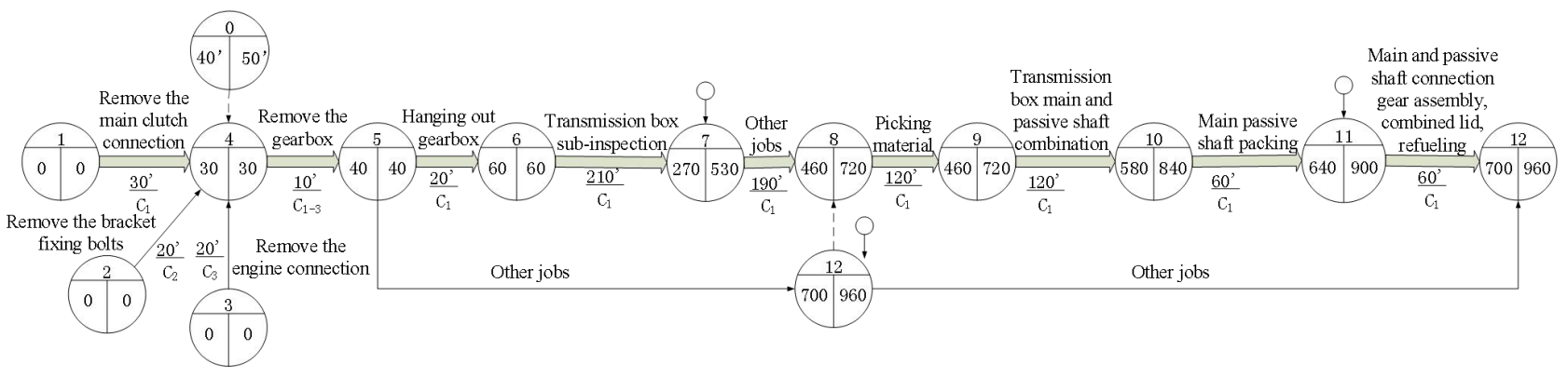

Fig. 2 Maintenance plan of gear box

\section{Medium Repair Process optimization}

From the above-mentioned co-ordination diagram, it can be seen that some of the processes are discontinuous, there are some processes can be parallel, so the repair process there is a further optimization of space. At the same time, the overall plan does not reflect the difference of the ability of maintenance workers, maintenance equipment, the efficiency of the impact, so the different personnel configuration scheme and different maintenance tools under the configuration of the total maintenance work hours and the cost of optimization analysis.

The different number of people and the same number of different types of work of the seven kinds of programs to study, respectively, the difference between the repair process, maintenance hours, working hours of the impact. Scenarios such as Table 4.

Table 4 Maintenance Personnel Configuration Program

\begin{tabular}{c|l|l|l|l}
\hline $\begin{array}{l}\text { Programme } \\
\text { serial number }\end{array}$ & Soldier & $\begin{array}{l}\text { Junior } \\
\text { workers }\end{array}$ & $\begin{array}{l}\text { Intermediate } \\
\text { workers }\end{array}$ & $\begin{array}{l}\text { Senior } \\
\text { workers }\end{array}$ \\
\hline 1 & 1 & 0 & 0 & 1 \\
\hline 2 & 0 & 1 & 0 & 1 \\
\hline 3 & 0 & 2 & 0 & 1 \\
\hline 4 & 0 & 1 & 1 & 1 \\
\hline 5 & 1 & 1 & 1 & 1 \\
\hline 6 & 1 & 2 & 1 & 1 \\
\hline 7 & 1 & 1 & 2 & 1 \\
\hline
\end{tabular}

In the case of programme four, there are three maintenance workers, the technical level being junior workers, intermediate workers and senior workers. According to the Personnel configuration optimization process, and according to each operation time and process constraints, calculate the different work time and the corresponding efficiency, the final access scheme shown in Figure 3. 


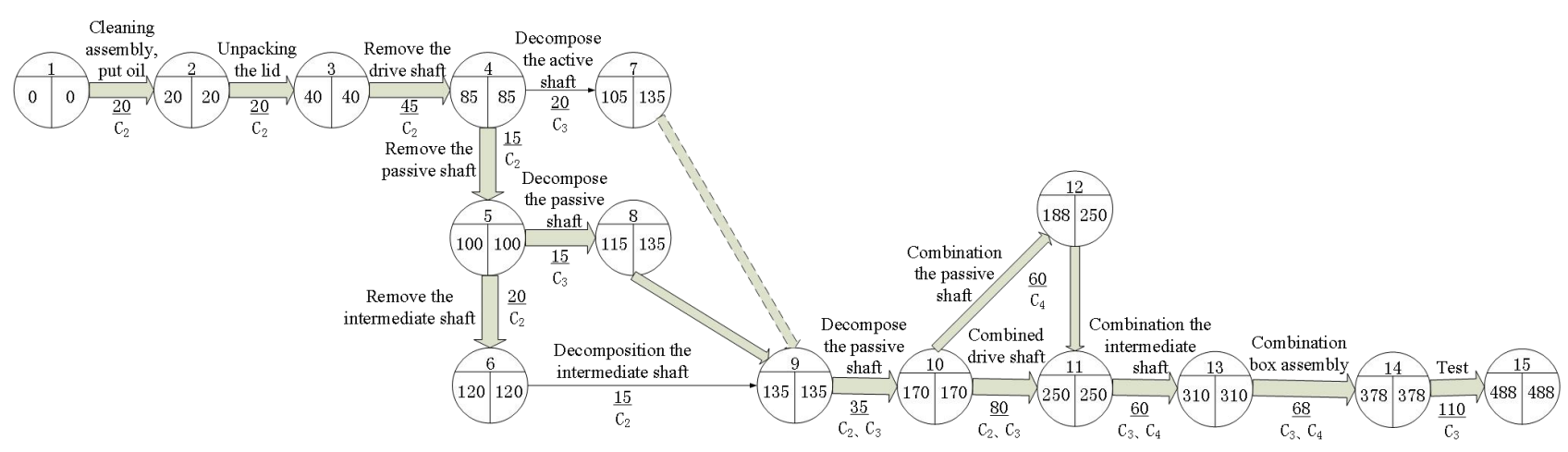

Fig. 3 Optimization of maintenance plan of gear box

In the same way, the total time to get seven maintenance programs is shown in table 5

Table 5 Maintenance Schedules

\begin{tabular}{c|l|l|l|l|c}
\hline $\begin{array}{l}\text { Programme } \\
\text { serial number }\end{array}$ & Soldier & $\begin{array}{l}\text { Junior } \\
\text { workers }\end{array}$ & $\begin{array}{l}\text { Intermediate } \\
\text { workers }\end{array}$ & $\begin{array}{l}\text { Senior } \\
\text { workers }\end{array}$ & $\begin{array}{c}\text { Total time } \\
\text { consuming (min) }\end{array}$ \\
\hline 1 & 1 & 0 & 0 & 1 & 450 \\
\hline 2 & 0 & 1 & 0 & 1 & 421 \\
\hline 3 & 0 & 2 & 0 & 1 & 373 \\
\hline 4 & 0 & 1 & 1 & 1 & 345 \\
\hline 5 & 1 & 1 & 1 & 1 & 328 \\
\hline 6 & 1 & 2 & 1 & 1 & 320 \\
\hline 7 & 1 & 1 & 2 & 1 & 315 \\
\hline
\end{tabular}

According to the table, with the maintenance personnel in the number and technical level of the upgrade, equipment maintenance period from $450 \mathrm{~min}$ to $315 \mathrm{~min}$, it is known that different personnel scheme configuration, the number and grade of maintenance workers in the equipment repair process has a greater impact. Compared to the 5,6,7, although the maintenance of the level and quantity of the upgrade can effectively reduce the total time spent on maintenance hours, but when the number increases to a certain extent, because of the impact of maintenance processes, maintenance hours will not be a significant reduction in the total time-consuming, already close to the ideal state. How to select the appropriate personnel configuration, but also combined with maintenance costs to do further analysis. The cost list for the process plan is shown in table 6

Table 6 Schedule of work expenses

\begin{tabular}{r|c}
\hline Configure scenario & Man-hour cost $¥)$ \\
\hline Programme 1 & 42.5 \\
\hline Programme 2 & 50.6 \\
\hline Programme 3 & 62.2 \\
\hline Programme 4 & 76.9 \\
\hline Programme 5 & 78.6 \\
\hline Programme 6 & 95.3 \\
\hline Programme 7 & 108.2 \\
\hline
\end{tabular}

Combined with total maintenance time and man-hour cost, the scheme was comprehensively analyzed: programme 1, 2 low cost, but the total time is long, the cost is high and the total time is long, programme 6,7 is always the shortest, but the cost of work is significantly higher; Programme 
4 is not the same as programme 5, and the total time consuming and cost of work is small, but programme 5 has a lower utilization rate of human resources,

The number and configuration of maintenance tools is also an important factor to affect the maintenance process, gear box repair mainly includes 12 types of general-purpose maintenance machine, tools, maintenance Tools configuration program table as shown in table 7.

Table 7 Maintenance tool configuration program

\begin{tabular}{l|c|c|c|c|c}
\hline \multicolumn{1}{c|}{ Programme } & Programme1 & Programme2 & Programme3 & Programme4 & Programme5 \\
\hline Open Wrench & 1 & 1 & 1 & 1 & 2 \\
\hline Socket Wrench & 1 & 1 & 1 & 1 & 2 \\
\hline Electric Wrench & 1 & 1 & 1 & 2 & 2 \\
\hline Copper Punch & 1 & 2 & 2 & 2 & 2 \\
\hline Big Hammer & 1 & 1 & 2 & 1 & 2 \\
\hline Small Hammer & 1 & 1 & 2 & 1 & 2 \\
\hline Flat Shovel & 1 & 1 & 1 & 2 & 2 \\
\hline Screwdriver & 1 & 1 & 1 & 2 & 2 \\
\hline Punch & 1 & 1 & 1 & 2 & 345 \\
\hline Press & 1 & 1 & 357 & 2 & 2 \\
\hline Air Compressor & 384 & 371 & 1 & 1 & 2 \\
\hline Man-hours(min) & 1 & 1 & 1 & 2 & 2 \\
\hline
\end{tabular}

Still choose the above program 4 personnel configuration, calculate different maintenance equipment to produce different maintenance hours, compared to the above five schemes, found that copper Chong, big hammer, small hammer, pressure machine These four types of machines or tools have a major impact on the maintenance process. For lower cost tools, in order to reduce maintenance hours, improve efficiency, as far as possible to configure more than two, for high cost or the maintenance of the limited impact of the tool can be appropriate to increase or maintain the status quo.

\section{Conclusion}

In this paper, the key steps of equipment repair--the replacement and repair of gear transmission box are studied, and the process of repair is evaluated and optimized. Firstly, the influence factors of the medium-repair process are put forward, and the quantification and evaluation methods of the main influencing factors are determined, and then the overall diagram of the repair process in the gear box is established. In view of the existing plan, combined with different personnel and maintenance equipment configuration to optimize the structure of the adjustment, the final determination of the gear box repair of the best resource allocation and maintenance process, and give a reasonable proposal for the equipment repair process to provide a new optimization ideas. Although this article carries on the optimization analysis to the medium repair process, but still has the question which waits for further research and the discussion, mainly has the following aspects:

1 , in the actual maintenance operation process in the middle of a lot of working procedures, the maintenance time is unknown, so that the uncertainty enhancement of maintenance hours, greatly reducing the credibility of the overall map.

2 , in the actual maintenance process may be part of the need to assist rather than the work done 
together, or must be completed by two people rather than double time to complete the work, and so on, in the co-ordination diagram is not reflected in the allocation of resources and the actual existence of a certain distance.

3 , the central repair plan and the middle repair process in the single maintenance process to give a determined work value, in fact, in the same maintenance technology level and equipment configuration conditions, the maintenance of the operation of the consumption of time is variable, the maintenance of the plan does not reflect the relative ability of the repair workers and personal preference.

\section{References}

[1] Li Aimin, Luo Jiulin, Fang Shiyuan. Some problems in [J]. Engineering Journal of ordnance equipment, armored equipment maintenance quality management in 2012, 33 (3): 65-66.

[2] Liu Wenbao. Tank repair technology [M]. Beijing: The Academy of Armored Forces Engineering, 1992.

[3] Intermediate repair process specification, [M]. general equipment department, general equipment support department,.2008,12

[4] Zong Fengbin, sun Lei. Factors affecting the quality of vehicle equipment maintenance and measures to improve maintenance quality [J]. automotive application, 2012 (4): 18-18.

[5] Tian Yan, Cheng Zhonghua, Jia Hongli. Analysis and method of influencing factors on equipment maintenance management reengineering [J]. Silicon Valley, 2010 (17): 76-76.

[6] Wang Tiening, Li Hao, Wang Shengfeng, et al. For the combat mission of armored equipment group carrying spares optimization configuration line [J]. Acta ARMAMENTARII, 2016,37 (10): 1881-1888.

[7] Lv Weizhen, Zhang Xueyan, Zheng Guoyu. Study on the demand for maintenance of armored equipment at basic level [J]. Journal of Ordnance Equipment Engineering, 2016 (8): 77-79.

[8] Liu Fusheng, Wu Wei, Dan Zhiwei, et al. Optimization model of availability and maintenance support cost for armored equipment [J]. Journal of The Academy of Armored Forces Engineering, 2010, 24 (4): 15-18.

[9] Zheng Wen. An overall plan analysis of the uncertain completion time of process [J]. Journal of Industrial and Commercial University Of Chongqing (NATURAL SCIENCE EDITION), 2013, 30 (6): 16-20.

[10] Wang Zilan, Wang Ciguang. Study on the planning method of shunting locomotive operation plan based on overall planning [J]. Journal of railway transportation and economics, 2012, 34 (1): $80-85$. 